\title{
BMJ Open Association between sense of coherence in adolescence and social benefits later in life: a 12-year follow-up study
}

\author{
Else Toft Würtz, ${ }^{1,3}$ Kirsten Fonager, ${ }^{1,2}$ Jens Tølbøll Mortensen ${ }^{1}$
}

To cite: Würtz ET, Fonager K, Mortensen JT. Association between sense of coherence in adolescence and social benefits later in life: a 12-year follow-up study. BMJ Open 2015;5: 006489.

doi:10.1136/bmjopen-2014006489

- Prepublication history for this paper is available online. To view these files please visit the journal online (http://dx.doi.org/10.1136/ bmjopen-2014-006489).

Received 3 September 2014 Revised 26 November 2014 Accepted 5 December 2014

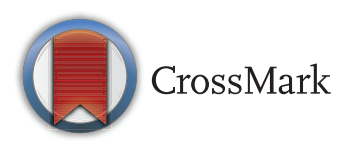

${ }^{1}$ Department of Social Medicine, Aalborg University Hospital, Aalborg, Denmark ${ }^{2}$ Faculty of Medicine, Department of Health Science and Technology, Aalborg University, Aalborg, Denmark ${ }^{3}$ Department of Occupational Medicine, Aalborg University Hospital, Aalborg, Denmark

Correspondence to Kirsten Fonager, Department of Social Medicine, Aalborg University Hospital, Havrevangen 1, 2, Post box 561, Aalborg DK-9100, Denmark; k.fonager@rn.dk

\section{ABSTRACT}

Objectives: Local government concerns over expenditure on social and healthcare are growing. The aim of the present study was to explore the association between a weak 'sense of coherence' (SOC) in teens and their subsequent risk of receiving social and healthcare benefits during young adulthood, and to monitor how SOC developed during this period.

Design: Prospective cohort study.

Setting: North Denmark Region.

Participants: 773 Pupils from seventh and eighth forms who answered a questionnaire in 1998.

Outcome measures: Different social benefits (from the Danish DREAM database embracing disbursed public social benefits). Change in SOC score from 1998 to 2010.

Results: 722 had answered seven items of the original SOC-13 questionnaire (denoted by SOC-7). Girls with a weak SOC-7 (the lowest 1st quartile) in 1998 had a significantly increased risk of receiving unemployment benefits (RR 1.3 (1.1 to 1.6)), social assistance (RR 1.8 (1.3 to 2.5)) and sickness benefits (RR 1.5 (1.2 to 2.0)) compared with girls with a strong SOC-7. For boys, only minor protective and non-significant differences were found. The SOC answers from 1998 and 2010 were compared $(n=394)$. SOC increased significantly and mostly in girls.

Conclusions: SOC-7 may serve as a predictor for social life event outcomes and hence facilitate an early identification and a selective approach to support teenage girls with a weak SOC. From adolescence to young adulthood, SOC-7 was of a relatively unstable nature.

\section{INTRODUCTION}

Supporting society's youngest citizens has both social and economic rationales. As youth employment in the age group 15-29 years has increased rapidly from $6 \%$ in 2008 to $13 \%$ in $2010,{ }^{1}$ it has contributed to local government concerns over social and healthcare expenditures.

Sense of coherence (SOC) was introduced in 1979 by Aaron Antonovsky as a salutogenic concept that captured the strength and determinants in health. ${ }^{2}$ The definition of SOC is:

\section{Strengths and limitations of this study}

- The study found a significant association between a weak sense of coherence (SOC) in adolescent girls and receiving social benefits in young adulthood using data with complete follow-up.

- No information about non-responders at baseline.

- The study could have been easier compared with other studies using the entire SOC-13 questionnaire in 1998.

A global orientation that expresses the extent to which one has a pervasive, enduring, though dynamic feeling of confidence that (1) the stimuli deriving from one's internal and external environments in the course of living are structured, predictable, and explicable; (2) the resources are available to one to meet the demands posed by these stimuli; and (3) these demands are challenges, worthy of investment and engagement. ${ }^{3}$

These three components are called comprehensibility, manageability and meaningfulness, respectively. The relationship between the components is dynamic in the sense that high manageability depends on comprehensibility. ${ }^{3}$

According to Antonovsky, a person's SOC is based on biological material and psychosocial phenomena and is a result of earlier life experiences until 30 years of age, and it remains relatively stable during life. ${ }^{3}$ The original 'orientation-to-life questionnaire' counted 29 items distributed on 11 items of comprehensibility, 10 items of manageability and eight items of meaningfulness (ie, SOC-29). A short version, SOC-13, comprising 13 of the original 29 items, was also developed. The SOC tool appears to be a reliable, valid and crossculturally applicable instrument measuring how people manage stressful situations and stay well. ${ }^{45}$ SOC seems, however, not to be as stable as was assumed by Antonovsky. ${ }^{5}$ Both Swedish and Danish studies have found that SOC-13 varies with age and gender in cross-sectional population studies. ${ }^{78}$ In general, men usually have a slightly stronger SOC than women. 
A strong SOC indicates that a person will be likely to cope more successfully with stressful situations. A strong SOC has been found to predict good health and to be related to a high quality of life. ${ }^{5}$ SOC also correlates with better school performance. ${ }^{9}$ Furthermore, SOC has been shown to have a negative correlation with anxiety and depression, a positive correlation with optimism and self-esteem, a moderate correlation with life events and to be connected with attitudes and behaviour. ${ }^{5}$ Other researchers have already addressed interventions to promote SOC. ${ }^{10} 11$

The aim of the present study was to explore the association between a weak SOC in teens and their subsequent risk of receiving social and healthcare benefits during young adulthood and to monitor how SOC developed during this period.

\section{METHODS}

Baseline

In 1998, the Department of Clinical Epidemiology, Aalborg Hospital, Aarhus University Hospital, Denmark completed a study of teenagers' use of over-the-counter painkillers. ${ }^{12}$ The basic population consisted of pupils from seventh and eighth forms in the former North Jutland County in Denmark. Selected public schools from districts with low, middle and high medicine use ${ }^{13}$ combined with rural and urban locations were invited to participate. Acceptance from 15 schools resulted in 1178 requests to fill in a selfadministrated questionnaire during a school lesson, corresponding to $12.7 \%$ of seventh and eighth form pupils in North Jutland County in 1998. ${ }^{14}$ Questions addressed issues about spare time, pain, use of painkillers, well-being, friends and selected SOC items. In 1998, the researchers selected seven of the original 13 SOC items from Antonovsky's SOC-1 $13^{3}$ (hereafter denoted by SOC-7). The seven items were those considered that the pupils would be capably answering given their age (no 1, 4-6, 8-9 and 13 from the SOC-13). The SOC-7 items were translated by JTM and a few phrases diverged slightly from the later Danish translation. ${ }^{15}$ Answers were given on a 7 -point Likert scale. The questionnaire also requested information on the Civil Registration System (CPR), which uniquely identifies all Danish citizens and was used for data linkage. The respondents' parents received a self-administered questionnaire on their occupation, pain, use of painkillers and satisfaction with life. The schools returned $802(68 \%)$ individual questionnaires from 433 girls and 369 boys of whom 699 also returned a parent questionnaire. The pupils' age varied from 12 to 16 (born 1982-1985).

\section{Follow-up}

Based on the CPR number, the 1998 participants were contacted again in 2010. We reached $773(96 \%)$. Those lost to follow-up included two whose CPR number was lacking, six who had died, 15 who had no available address and six mail deliveries that failed.

Data were linked to the Danish DREAM database where information on all public social benefits are registered on a weekly basis and can be linked to the individual recipient via the CPR number. The DREAM database contains pooled data from all relevant Danish ministries, all Danish municipalities and the national bureau of statistics (Statistics Denmark) since July 1991 and the database has been found suitable for public health research. ${ }^{16}$ The DREAM database has 110 different codes which cover benefits disbursed within any given week to a citizen whether he or she has received the benefit during a single day or the whole week. It is only possible to have one registration per week in a given benefit priority.

A personal letter with an internet address and a personal identification code was mailed to each follow-up participant and, if necessary, a reminder was mailed 1 month later. The internet-based questionnaire contained the SOC-13 questionnaire and 48 other questions considering self-reported health (SF12), medicine use, alcohol (Cage-C) and smoking habits, diet, physical activity, height, weight and education.

\section{Ethical considerations}

The study was conducted in accordance with the World Association's Declaration of Helsinki. The participants and their parents signed a consent form and accepted participation in a later follow-up study. In 2010, the North Denmark Region approved and notified the Danish Data Protection Agency about the follow-up study.

\section{Statistical analyses}

Only participants who had answered all SOC-7 items in 1998 were included. The SOC scores were dichotomised into first (weak) and second-to-fourth quartile (strong) SOC. No 'normal' level of SOC was suggested by Antonovsky, and little agreement seems to exist on how to set SOC levels. Still, several studies have used the lowest $25 \%$ of the scores to characterise the weak group. ${ }^{5}$ DREAM data were extracted from the years 2000 to 2009 and categorised in primary and secondary groups as shown in table 1.

The risk of receiving different social benefits was analysed using two different categories: (1) Any social benefit received, (2) Long duration of social benefit (unemployment benefit $>6$ months, social assistance $>3$ months, and sickness benefit $>3$ months). Bivariate associations were tested with $\chi^{2}$ statistics. The association between a weak SOC as a teen and the risk of receiving social benefits in young adulthood was assessed by relative risk (RR) estimates. However, since it was possible to receive more than one type of social benefits during the study period, restricted analyses were performed that compared participants with a specific benefit with participants receiving no benefit at all in the study period. The internal consistency reliability of the SOC scale items were measured with Cronbach's $\alpha$ coefficient. In order to compare SOC in 1998 with SOC in 2010, the test-retest correlation was measured with Pearson's correlation coefficient. Only participants who answered the SOC-7 items in 2010 were included. The statistical 
Table 1 Selected codes for social benefits in the DREAM database and participants in groups 2000 throughout 2009

\begin{tabular}{|c|c|c|c|c|}
\hline Primary group & Code & Social benefit & Secondary group & $\begin{array}{l}N=773 \\
N(\%)\end{array}$ \\
\hline$A$ & $\left.\begin{array}{l}111-113 \\
131-136,139 \\
141-146 \\
\\
211-216 \\
221-222,224 \\
297-299\end{array}\right\}$ & $\begin{array}{l}\text { Unemployment benefit } \\
\text { Unemployment benefit if social } \\
\text { assistance* }^{*} \\
\text { Unemployment benefit if subsidised }_{\text {employment }^{\dagger}} \\
\text { Subsidised employment† }\end{array}$ & Unemployment benefit & $379(49)$ \\
\hline B & $\begin{array}{l}730-736,739 \\
751-759 \\
791\end{array}$ & $\begin{array}{l}\text { Social assistance* } \\
\text { Vocational social assistance } \\
\text { Vocational rehabilitation benefit }\end{array}$ & Social assistance & $161(21)$ \\
\hline $\mathrm{C}$ & $891-895$ & Sickness benefitł & Sickness benefit & $286(37)$ \\
\hline $\mathrm{D}$ & $\begin{array}{l}761-762,769 \\
793\end{array}$ & $\begin{array}{l}\text { Light job§ } \\
\text { Disability pension }\end{array}$ & Permanent health-related benefit & $4(0.5)$ \\
\hline$E$ & $\begin{array}{l}741-744,746,749 \\
771-773,779\end{array}$ & $\begin{array}{l}\text { Unemployed after 'flex job'ף } \\
\text { 'Flex job'ף }\end{array}$ & & \\
\hline
\end{tabular}

*Social benefit administered by the municipal social service department. Amount based on calculation of economic needs. Payment normally requires active job seeking through the Public Employment Service.

†Paid by the Public Employment Service to the employer of a long-term unemployed person.

¥Municipally administered benefit paid to a person or transferred to an employer if the employer pays a normal wage to a sick-listed employee.

§Jobs for citizens receiving disability pension. Jobs are on special terms as regards pay and working hours. Normally, only a few hours weekly.

TJobs created for persons with limited work capacity. Person receives a normal wage and the benefit is transferred to the employer. $\mathrm{N}$ : number in secondary group: a person may be present in several groups.

significance level was set at $\mathrm{p}<0.05$ and CIs of $95 \%$ were reported. Analyses were completed in STATA V.9.2.

\section{RESULTS}

The baseline SOC-7 range and mean (SD) was 9-49, 36.2 (7.1), respectively, and were significantly higher in boys (18-49, $37.8(6.4))$ compared with girls (9-49, 35.0 (7.4)). The scale reliability coefficient of the SOC-7 items from 1998 was 0.77 (boys 0.73 and girls 0.79). Baseline data (table 2) were stratified according to answers to the SOC-7 items: Answering<seven items, First quartile and second-fourth quartiles.

Significant differences between the first quartile and the second-fourth quartiles were seen in terms of gender, number of siblings, health, enough time, feeling rested and having a good friend. The distribution was more equal for age, form, spare time, living and the parents' satisfaction with life.

DREAM data were available for all reached 773 participants in 2010. The distribution of the participants in DREAM groups appears in table 1 . It should be noted that a respondent could be registered in several groups in the time span. According to the selected codes of interest, 266 participants had no entry in DREAM from 2000 until the end of 2009. In all, $49 \%$ had received unemployment benefit, $21 \%$ social assistance, $37 \%$ sickness benefit and $0.5 \%$ permanent health-related benefit. A total of 722 pupils had answered all SOC-7 items in 1998. Among the 51 pupils (773-722) who disregarded some or all SOC-7 items in 1998, significantly more pupils were boys and more pupils were missing 'a good friend' than among the 722 answering all the SOC-7 items. Girls $(\mathrm{n}=21)$ more frequently received social assistance $(38 \%$ vs $25 \%$ ) and sickness benefit (52\% vs $37 \%$ ) later in life compared to girls who completed SOC-7. In contrast, boys $(n=30)$ received less sickness benefits $(23 \%$ vs $37 \%)$ later in life compared to boys who completed SOC-7.

At follow-up, 57\% (441 out of 773) answered the internet-based questionnaire and $394(94 \%)$ had answered the same SOC-7 items as in 1998. The range, mean (SD) and the scale reliability coefficient of the SOC-7 items were 16-49, $39.6(7.3)$ and 0.84, respectively (Girls: 16-49, 39.3 (7.5) and 0.85; boys: 16-49, 40.0 (7.0) and 0.82). SOC-7 increased significantly from 1998 to 2010 , mostly in the girls. Mean differences in SOC-7 were 3.7 for girls and 1.8 for boys. The 332 non-responders in 2010 were significantly more often males than females, more often in the weak than in the strong SOC-7 group, and had an increased risk of receiving social benefits and sickness benefits later in life compared with those who completed the questionnaire. The equivalent values within the SOC-13 items were 31-84, $67.0(9.9)$ and 0.89 , respectively (Girls: 31-84, 67.0 (9.9) and 0.89; boys: 35-83, 67.5 (10.0) and 0.89). Using all the SOC-13 items seemed to eliminate the scale reliability gender difference observed with SOC-7.

\section{SOC and social benefits}

Girls had more often received any kind of social benefit than boys (table 3). Compared with girls with a strong SOC-7, girls with a weak SOC-7 had a significantly 
Table 2 Description of study population in 1998 stratified on answers to sense of coherence questions

\begin{tabular}{|c|c|c|c|c|}
\hline & \multicolumn{3}{|l|}{ SOC-7* } & \multirow[b]{2}{*}{$\begin{array}{l}\text { Total } \\
\mathrm{N}=773 \\
\mathrm{~N}(\%)\end{array}$} \\
\hline & $\begin{array}{l}<7 \text { items } \\
\mathrm{N}=51 \\
\mathrm{~N}(\%)\end{array}$ & $\begin{array}{l}\text { 1st quartile } \\
\mathrm{N}=181 \\
\mathrm{~N}(\%)\end{array}$ & $\begin{array}{l}\text { 2nd-4th quartiles } \\
N=541 \\
N(\%)\end{array}$ & \\
\hline Age, mean (SD) & $14(0.8)$ & $13.9(0.7)$ & $13.9(0.7)$ & $13.9(0.7)$ \\
\hline \multicolumn{5}{|l|}{ Gender } \\
\hline Boys & $30(59) \dagger$ & $56(31) \ddagger$ & $266(49)$ & $352(46)$ \\
\hline \multicolumn{5}{|l|}{ Form } \\
\hline 7th & $24(47)$ & $75(41)$ & $234(43)$ & $333(43)$ \\
\hline \multicolumn{5}{|l|}{ Living } \\
\hline Rural & $26(51)$ & $87(48)$ & $255(47)$ & $368(48)$ \\
\hline With mum and dad & $36(78)$ & $132(73)$ & $420(78)$ & $588(77)$ \\
\hline \multicolumn{5}{|l|}{ Siblings } \\
\hline $0-2$ & $37(84)$ & $121(72) \ddagger$ & $415(82)$ & $573(80)$ \\
\hline \multicolumn{5}{|l|}{ Spare time } \\
\hline Practise sport & $34(77)$ & $122(70)$ & $396(76)$ & $552(75)$ \\
\hline Have work & $28(65)$ & $109(64)$ & 301 (59) & $438(60)$ \\
\hline \multicolumn{5}{|l|}{ Health } \\
\hline Healthy§ & $39(89)$ & $131(80) \ddagger$ & $444(87)$ & $614(86)$ \\
\hline \multicolumn{5}{|l|}{ Well-being } \\
\hline Good everyday lifeף & $43(96)$ & $168(93)$ & $540(100)$ & $751(98)$ \\
\hline Enough time ${ }^{\star *}$ & 41 (89) & 155 (86)‡ & $515(96)$ & 711 (93) \\
\hline Feel rested†† & $29(67)$ & $90(51) \ddagger$ & $350(65)$ & 469 (62) \\
\hline Have a good friendł‡ & $42(93) \dagger$ & $170(96) \ddagger$ & $529(99)$ & 741 (98) \\
\hline \multicolumn{5}{|l|}{ Parents $(\mathrm{N}=682)$} \\
\hline Satisfied with life§§ & $44(96)$ & $147(94)$ & $454(95)$ & $645(95)$ \\
\hline \multicolumn{5}{|c|}{ 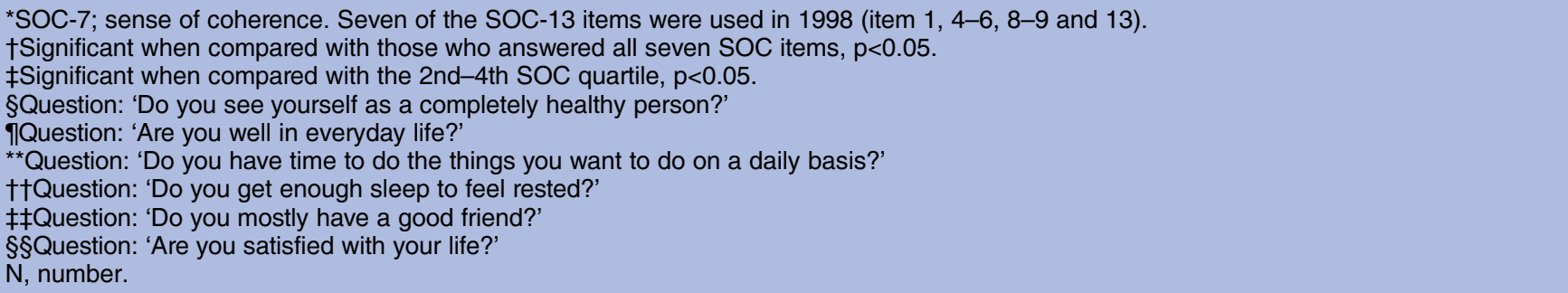 } \\
\hline
\end{tabular}

increased $\mathrm{RR}$ of receiving unemployment benefits (RR 1.3; $95 \%$ CI 1.1 to 1.6 ), social assistance (RR 1.8; $95 \%$ CI 1.3 to 2.5 ) and sickness benefit (RR $1.5 ; 95 \%$ CI 1.2 to 2.0), but non-significant permanent health-related benefits (RR 6.6; $95 \%$ CI 0.7 to 62.8; table 3). Excluding participants receiving one of the other social benefits listed in table 1 did not change the estimates, except for the permanent health-related benefit which significantly exhibited an increased risk. Girls' excess risk of receiving social benefits was increased even further in the long term (table 4). For boys, only minor non-significant protective differences were found between the SOC-7 groups.

\section{SOC and self-rated health}

Self-rated health was explored in 2010 by the question: 'In general, would you say your health is...' and answers were 9\% 'Excellent', 48\% 'Very good', 33\% 'Good', 8\% 'Fair' and 1\% 'Poor' $(\mathrm{n}=432)$. Having a weak SOC-7 in 1998 significantly increased the risk that the participants would rate their health as fair or poor compared with excellent, very good or good (RR 1.99 (95\% CI 1.03 to 3.86); $\mathrm{n}=409$ ).

\section{Test-retest of SOC}

Pearson's correlation coefficients were equal among boys and girls $(0.31$ and 0.30$)$. This corresponds to an imperfect positive correlation between SOC-7 due to actual changes in the populations' SOC-7 scores. Figure 1 shows the SOC-7 items from 1998 and 2010 scored as continuous variables $(n=394)$. Notable changes were observed: $35 \%$ of the girls and $27 \%$ of the boys changed the SOC-7 group. The change from a weak 1998 to a strong 2010 SOC-7 was more prominent among boys (64\%) than among girls (58\%), whereas the girls accounted for the largest change from a high 1998 to a weak 2010 SOC-7 (27\%) against the identical change in boys $(21 \%)$.

\section{DISCUSSION}

A weak SOC-7 among girls in their teenage years increased their risk of becoming recipients of all the social benefits analysed in this study. All respondents had an increased risk of having a fair or poor self-rated health in 2010 if they had a weak SOC-7 in 1998. SOC-7 
Table 3 Young adult's risk of receiving any selected social benefits later in life (2000-2009) if having a weak sense of coherence (SOC-7) in 1998 (N=722)

\begin{tabular}{|c|c|c|c|c|c|c|c|c|}
\hline & \multicolumn{4}{|l|}{ Female } & \multicolumn{4}{|l|}{ Male } \\
\hline & $\begin{array}{l}\text { 1st } \\
\text { quartile } \\
\text { SOC } \\
\mathrm{N}=125 \\
\text { Per cent }\end{array}$ & $\begin{array}{l}\text { 2nd-4th } \\
\text { quartile } \\
\text { SOC } \\
\mathrm{N}=275 \\
\text { Per cent }\end{array}$ & $\mathbf{R R}(95 \% \mathrm{Cl})$ & $\mathrm{RR}^{\star}(95 \% \mathrm{Cl})$ & $\begin{array}{l}\text { 1st } \\
\text { quartile } \\
\text { SOC } \\
\mathrm{N}=56 \\
\text { Per cent }\end{array}$ & $\begin{array}{l}\text { 2nd-4th } \\
\text { quartile } \\
\text { SOC } \\
\mathrm{N}=266 \\
\text { Per cent }\end{array}$ & RR $(95 \%$ Cl) & $\mathbf{R R}^{*}(95 \% \mathrm{Cl})$ \\
\hline Unemployment benefit (table 2: A) & 57 & 43 & $1.32(1.08$ to 1.62$)$ & 1.37 (1.15 to 1.64$)$ & 43 & 53 & 0.81 (0.59 to 1.12$)$ & $0.91(0.68$ to 1.21$)$ \\
\hline Social assistance (table 2: B) & 35 & 20 & 1.76 (1.26 to 2.46$)$ & 1.81 (1.36 to 2.41$)$ & 14 & 16 & 0.90 (0.45 to 1.82$)$ & 0.92 (0.49 to 1.73$)$ \\
\hline Sickness benefit (table 2: C) & 49 & 32 & 1.53 (1.19 to 1.96$)$ & 1.52 (1.23 to 1.88$)$ & 43 & 36 & 1.20 (0.85 to 1.69$)$ & 1.07 (0.80 to 1.45$)$ \\
\hline $\begin{array}{l}\text { Permanent health-related benefit } \\
\text { (table 2: } D+E \text { ) }\end{array}$ & 2.4 & 0.4 & 6.60 (0.69 to 62.8$)$ & $10.27(1.10$ to 95.5$)$ & 0 & 0 & - & - \\
\hline
\end{tabular}

Table 4 Young adult's risk of receiving selected social benefits for at least 3 months ${ }^{\star}$ later in life (2000-2009) if having a weak sense of coherence (SOC-7) in 1998 $(\mathrm{N}=722)$

\begin{tabular}{|c|c|c|c|c|c|c|c|c|}
\hline & \multicolumn{4}{|l|}{ Female } & \multicolumn{4}{|l|}{ Male } \\
\hline & $\begin{array}{l}\text { 1st } \\
\text { quartile } \\
\text { SOC } \\
\mathrm{N}=125 \\
\text { Per cent }\end{array}$ & $\begin{array}{l}\text { 2nd-4th } \\
\text { quartile } \\
\text { SOC } \\
\mathrm{N}=275 \\
\text { Per cent }\end{array}$ & RR (95\% Cl) & $\mathrm{RR}+(95 \% \mathrm{Cl})$ & $\begin{array}{l}\text { 1st } \\
\text { quartile } \\
\text { SOC } \\
\mathrm{N}=56 \\
\text { Per cent }\end{array}$ & $\begin{array}{l}\text { 2nd-4th } \\
\text { quartile } \\
\text { SOC } \\
\mathrm{N}=266 \\
\text { Per cent }\end{array}$ & RR (95\% Cl) & $\mathrm{RR}+(95 \% \mathrm{Cl})$ \\
\hline Unemployment benefit (table 2: A) & 39 & 21 & 1.89 (1.38 to 2.60$)$ & 1.89 (1.41 to 2.53$)$ & 11 & 26 & $0.42(0.19$ to 0.92$)$ & $0.47(0.22$ to 1.01$)$ \\
\hline Social assistance (table 2: B) & 30 & 15 & $2.04(1.38$ to 3.00$)$ & 2.23 (1.53 to 3.23$)$ & 7 & 11 & $0.66(0.24$ to 1.79$)$ & $0.61(0.23$ to 1.65$)$ \\
\hline Sickness benefit (table 2: C) & 30 & 15 & 2.09 (1.41 to 3.09$)$ & 2.35 (1.64 to 3.37$)$ & 11 & 19 & 0.57 (0.26 to 1.26$)$ & $0.68(0.32$ to 1.46$)$ \\
\hline
\end{tabular}


Figure 1 Sense of coherence (SOC) among 394 participants answering the same seven items of the SOC-13 questionnaire (no. $1,4-6,8-9$ and 13) in 1998 and 2010. Dotted lines separate the 1 st and 2 nd -4 th quartiles of SOC-7.

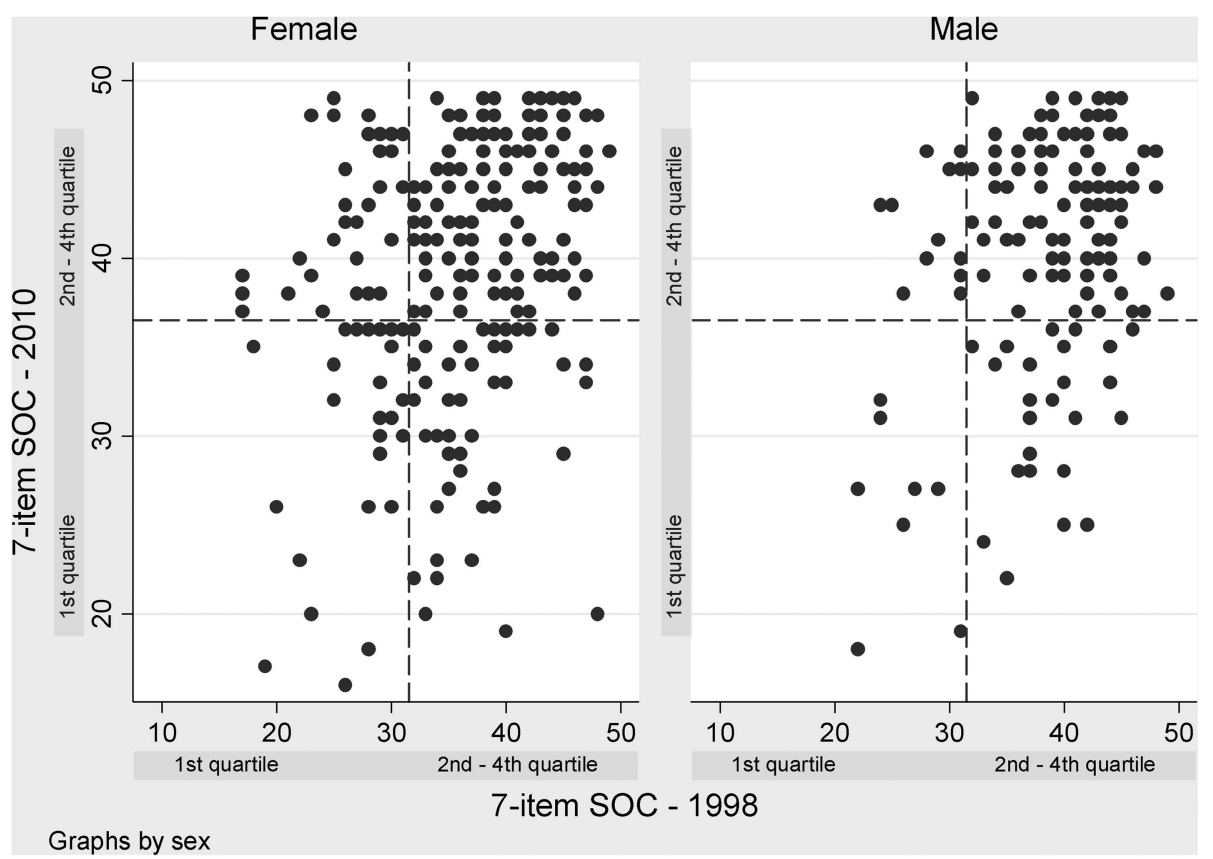

appeared to be somewhat unstable with a significant increase during the study period, especially in females.

The 1998 response rate was $68 \%$ and we had no information on non-responders. The selected sample and low response rate may reduce our ability to make general conclusions on the basis of the estimations. Looking at SOC-7 non-responders, we found them to be similar in terms of living, spare time and health to those who had answered all the SOC-7 items. However, girls answering less than seven SOC-7 items more frequently received social assistance and sickness benefits later in life than those who answered all the SOC-7 questions, while the 30 boys received less sickness benefit later in life compared to those who answered all seven SOC items. Furthermore, selection bias regarding the participating schools could not be rejected, although urban and rural schools are present. The differences in scale reliability coefficients between boys and girls $(0.73$ and 0.79 , respectively) at baseline support the common a priori belief that girls are more mature than boys in seventh and eighth forms given the more coherent answers, while the equal coefficients for SOC-13 in 2010 but not SOC-7 might rather point to a matter of selected questions.

A main strength of this study is the complete follow-up in DREAM data. The response rate for the follow-up questionnaire was $57 \%$, considered low, but expectable in a 12-year follow-up study, with no further contact with the participants. However, we believe that the internetbased questionnaire was ideal for this young target group and would not expect an increased response using an ordinary hard copy format. The mean SOC in 2010 may have been overestimated because a large fraction of 2010 non-responders had a comparatively weak SOC-7 score in 1998. During the study period, the international financial crisis may have increased the need for social benefits in general. This may have entailed an underestimation of the association between a 'normal' risk of receiving social benefits later in life and having had a weak SOC-7.

The most favourable basis on which this study could have been compared with other studies would have been in 1998 to use the entire SOC-13 questionnaire which is applicable to children from 12 years. ${ }^{17}$ No other studies have been identified using the SOC-7 items used for the baseline study. Several studies have used all SOC-13 questions, ${ }^{17-19}$ or the modified children's scale,${ }^{20} 21$ for teenagers aged 11-16 years. The internal consistency reliability of the SOC scale was $0.81-0.87$ in these studies. The present baseline study had a slightly lower Cronbach's $\alpha$ of 0.77 for the selected SOC-7 items, which might be explained by our use of fewer items. ${ }^{5}$ Other studies have described a significantly higher SOC in boys than in girls as seen in the baseline data of this study. ${ }^{19} 2122$

Longitudinal studies using SOC as a predictor of social benefits are few. A Finnish study using 16 items of SOC-29 predicted that having a one-point decrease in SOC would increase the risk for disability pension by $1.5 .^{23}$ In another study, Finnish employees answered six items from SOC-29 and a weak SOC significantly predicted sickness absence in females. ${ }^{24}$

In a review of SOC and its association with health, Eriksson and Lindstrom concluded that SOC seems to be a health-promoting resource. ${ }^{25}$ This study supports this view because the respondents had an increased risk of rating their health as fair or poor if they had a weak SOC-7.

Our study had a low test-retest correlation coefficient (0.31) as evidenced by a significant change in SOC-7 over 12 years and by the fact that a large number of participants changed the SOC-7 group, which reflects the relatively unstable nature of SOC-7 in this age group. 
Cross-sectional studies have attributed a change in the SOC score in different age groups to cohort effects, health selection or life experience. ${ }^{7} 8$ The follow-up design adopted in this study eliminated the cohort effect and health selection by demonstrating a true age effect. Moreover, our results confirm the findings from other longitudinal studies which have reported test-retest correlation coefficients between 0.42 and 0.77 with up to 10 years of follow-up. ${ }^{5}$ Additionally, SOC seems to be more stable in older age groups. ${ }^{26}{ }^{27}$ The low correlation coefficient in our study is probably due to the comparatively young age of the study group. Previous crosssectional studies of adolescents have reported negative associations between SOC and use of medicine, persistent depressive symptoms and generalised anxiety, and subjective health problems. ${ }^{20-22} 28$ This is in agreement with our study since social benefits might be an indicator of health problems.

To the best of our knowledge, no similar studies have reported that a weak SOC in girls may be a predictor for receiving social benefits later in life, and further studies are therefore needed. One could construct a hypothesis that the SOC-7 answers from 1998 actually reflect the girls being more conscious of their life situation. Intervention studies targeting adolescent girls with a weak SOC may contribute valuable knowledge that will allow us to test or design instruments for supporting these girls.

\section{CONCLUSION}

This study found a significant association between a weak SOC-7 in adolescent girls and receiving social benefits in young adulthood. These findings may suggest that SOC may serve as a predictor for social life event outcomes and may hence facilitate an early identification and a selective approach to supporting teenage girls with a weak SOC. From adolescence to young adulthood, SOC-7 seemed to be relatively unstable.

Contributors ETW and KF participated in planning and accomplishing the follow-up study, statistics and manuscript revision. JTM was involved in planning and accomplishing the baseline study, was counsellor in the follow-up study and took part in manuscript revision.

Funding The authors would like to thank The North Denmark Region for their contribution with DREAM data. The research was supported by 'Det kommunale Momsfond' in Denmark (Id 000213102).

Competing interests None.

Ethics approval The study was approved by the former Scientific Ethical Committee for the counties of Viborg and North Jutland and the Danish Data Protection Agency in 1998.

Provenance and peer review Not commissioned; externally peer reviewed.

Data sharing statement No additional data are available.

Open Access This is an Open Access article distributed in accordance with the Creative Commons Attribution Non Commercial (CC BY-NC 4.0) license, which permits others to distribute, remix, adapt, build upon this work noncommercially, and license their derivative works on different terms, provided the original work is properly cited and the use is non-commercial. See: http:// creativecommons.org/licenses/by-nc/4.0/

\section{REFERENCES}

1. The Nordic Social Statistical Committee. Youth Unemployment in the Nordic Countries-A Study on the Rights of and Measures for Young Jobseekers. 2011. http://nososco-eng.nom-nos.dk/filer/ publikationer/Youth\%20Unemployment.pdf (accessed 30 Jul 2012).

2. Antonovsky A. Health, stress and coping. 2nd edn. San Francisco: Jossey-Bass, 1979:255.

3. Antonovsky A. Unraveling the mystery of health: how people manage stress and stay well. San Francisco: Jossey-Bass, 1987:218.

4. Antonovsky A. The structure and properties of the sense of coherence scale. Soc Sci Med 1993;36:725-33.

5. Eriksson M, Lindstrom B. Validity of Antonovsky's sense of coherence scale: a systematic review. J Epidemiol Community Health 2005;59:460-6.

6. Nilsson KW, Leppert J, Simonsson B, et al. Sense of coherence and psychological well-being: improvement with age. J Epidemiol Community Health 2010;64:347-52.

7. Lindmark U, Stenstrom U, Gerdin EW, et al. The distribution of 'sense of coherence' among Swedish adults: a quantitative cross-sectional population study. Scand J Public Health 2010;38:1-8.

8. Due EP, Holstein BE. "Sense of coherence", socialgruppe og helbred i en dansk befolkningsundersøgelse. Ugeskr Laeger 1998;160:7424-9. Danish.

9. Kristensson P, Ohlund LS. Swedish upper secondary school pupils sense of coherence, coping resources and aggressiveness in relation to educational track and performance. Scand J Caring Sci 2005; 19:77-84.

10. Mayer $\mathrm{CH}$, Boness $\mathrm{C}$. Interventions to promoting sense of coherence and transcultural competences in educational contexts. Int Rev Psychiatry 2011;23:516-24.

11. Endo S, Kanou H, Oishi K. Sports activities and sense of coherence (SOC) among college students. Int J Sport Health Sci 2012;10:1-11

12. Mortensen JT, Bendsen J. Børn og unges anvendelse af smertestillende medicin i Nordjyllands Amt 1998. Danish.

13. Nielsen A. Børns sundhed i Danmark. Copenhagen: DIKE, 1998 Danish:350.

14. Ministry of Education. Folkeskolen i tal 1997/98 Planlægningstal. 1999. Danish. http://pub.uvm.dk/1999/folkeskolenital/ (accessed 31 Jul 2012).

15. Antonovsky A. Helbredets mysterium: at tåle stress og forblive rask. 1st edn. Copenhagen: Hans Reitzel, 2000. Danish:231.

16. Hjøllund NH, Larsen FB, Andersen JH. Register-based follow-up of social benefits and other transfer payments: accuracy and degree of completeness in a Danish interdepartmental administrative database compared with a population-based survey. Scand J Public Health 2007;35:497-502.

17. Honkinen PL, Suominen S, Rautava P, et al. The adult sense of coherence scale is applicable to 12-year-old schoolchildrenan additional tool in health promotion. Acta Paediatr 2006;95:952-5.

18. Freire MC, Sheiham A, Hardy R. Adolescents' sense of coherence, oral health status, and oral health-related behaviours. Community Dent Oral Epidemiol 2001;29:204-12.

19. Dorri M, Sheiham A, Hardy R, et al. The relationship between sense of coherence and toothbrushing behaviours in Iranian adolescents in Mashhad. J Clin Periodontol 2010;37:46-52.

20. Torsheim T, Aaroe LE, Wold B. Sense of coherence and school-related stress as predictors of subjective health complaints in early adolescence: interactive, indirect or direct relationships? Soc Sci Med 2001:53:603-14.

21. Koushede V, Holstein BE. Sense of coherence and medicine use for headache among adolescents. J Adolesc Health 2009;45:149-55.

22. Moksnes UK, Rannestad T, Byrne DG, et al. The association between stress, sense of coherence and subjective health complaints in adolescents: sense of coherence as a potential moderator. Stress Health 2011;27:e157-65.

23. Suominen S, Gould R, Ahvenainen J, et al. Sense of coherence and disability pensions. A nationwide, register based prospective population study of 2196 adult Finns. J Epidemiol Community Health 2005:59:455-9.

24. Kivimäki M, Feldt T, Vahtera J, et al. Sense of coherence and health: evidence from two cross-lagged longitudinal samples. Soc Sci Med 2000;50:583-97. 
25. Eriksson M, Lindstrom B. Antonovsky's sense of coherence scale and the relation with health: a systematic review. J Epidemiol Community Health 2006;60:376-81.

26. Richardson CG, Ratner PA, Zumbo BD. A test of the age-based measurement invariance and temporal stability of Antonovsky's sense of coherence scale. Educ Psychol Meas 2007;67:679-96.
27. Feldt $\mathrm{T}$, Lintula $\mathrm{H}$, Suominen $\mathrm{S}$, et al. Structural validity and temporal stability of the 13-item sense of coherence scale: prospective evidence from the population-based HeSSup study. Qual Life Res 2007;16:483-93.

28. Henje Blom EC, Serlachius E, Larsson JO, et al. Low sense of coherence (SOC) is a mirror of general anxiety and persistent depressive symptoms in adolescent girls-a cross-sectional study of a clinical and a non-clinical cohort. Health Qual Life Outcomes 2010;8:58. 